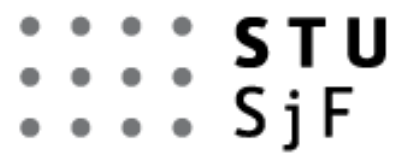
DE GRUYTER
OPEN

\section{Journal of MECHANICAL ENGINEERING - Strojnícky časopis}

VOLUME 66, NO 2, 2016

pp. $13-22$

DOI: $10.1515 /$ scjme-2016-0014

\title{
NUMERICAL CALCULATION OF OVERHEAD POWER LINES DYNAMICS
}

\author{
GOGOLA Roman ${ }^{1}$, MURÍN Justín ${ }^{1}$, HRABOVSKÝ Juraj ${ }^{1}$ \\ ${ }^{1}$ Slovak University of Technology in Bratislava, Faculty of Electrical Engineering and Information Technology, \\ Department of Applied Mechanics and Mechatronics, Ilkovičova 3, 81219 Bratislava, Slovakia, \\ xgogolar@stuba.sk,justin.murin@stuba.sk
}

\begin{abstract}
This paper contains results of transient analysis of airflow around the ACSR power line cross-section in unsymmetric multi-span. The forces applied to the power line are obtained from CFD simulations, where the wind induced vibration is studied. Effect of these forces to the maximal displacement of the power line and the maximal mechanical forces in the points of attachment are studied and evaluated.
\end{abstract}

KEYWORDS: ACSR conductor, homogenization, CFD, FEM, transient analysis

\section{Introduction}

Vibration and oscillations of overhead power lines is a very dangerous problem because it can cause mechanical damage of the conductors, insulators, armatures and power line pylons. They can negatively influence the whole power transmission system and can make a power transmission system collapse. They can be classified into three groups: aeolian, galloping and subspan oscillations [1].

- Aeolian vibration is caused by vortex shedding behind the conductor, where the frequency of vortex shedding is given by the Strouhal number. Aeolian vibration occurs in low to moderate winds, and has an amplitude comparable to the conductor diameter.

- Galloping occurs in medium to high winds and if ice or snow builds up on the conductor and creates an aerodynamically unstable shape. This can give large forces and moments on the conductor. The most violent galloping occurs if the torsional eigenfrequency of the line is close to one of the lower eigenfrequencies for vertical vibrations of the line [1].

- Sub-span oscillation is a phenomenon that occurs on bundled conductors, where the vortex shedding wake hits one of the other conductors and this conductor starts to oscillate.

Vibration and oscillations of overhead power lines is investigated by many authors. Large amplitude vibrations of long-span transmission lines with bundled conductors in gusty wind is studied in [2]. In [3], the impact of wind-induced vibration coefficient of transmission tower is presented. The issue of line vibration and galloping of power lines is presented e.g. in [4] and in [5] numerical simulation of galloping by means of ABAQUS software is presented.

Airflow around the ACSR power line conductors is difficult physical tasks. The flow behind the conductor starts to oscillate and single vortices are periodically separated and dragged with the rest of the flow. This is called von Karman Vortex Street (Fig. 1). It's time periodically recurring unstable vortex structures that arise behind the conductor under 
constant input parameters (constant air velocity and mild turbulence). For the situations of air flow around the overhead power lines in multi-span it is necessary to perform an experiment or a simulation [1].

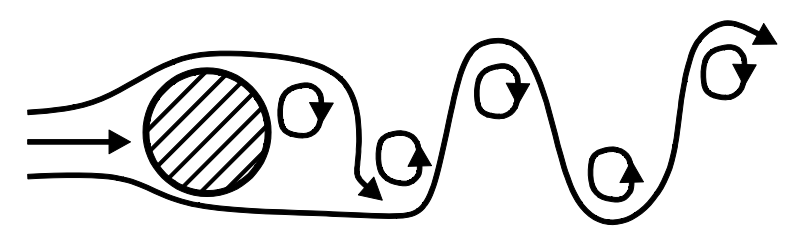

Fig. 1 Schematic representation of Karman Vortex Street behind a conductor

\section{Modelling of airflow around the ACSR conductor}

A model (tunnel) for modelling and simulation of forces caused by airflow around the power line cross-section was created in software ANSYS CFX [6]. Here, a horizontal constant flow of air in the direction from left to right was applied (Fig. 2).

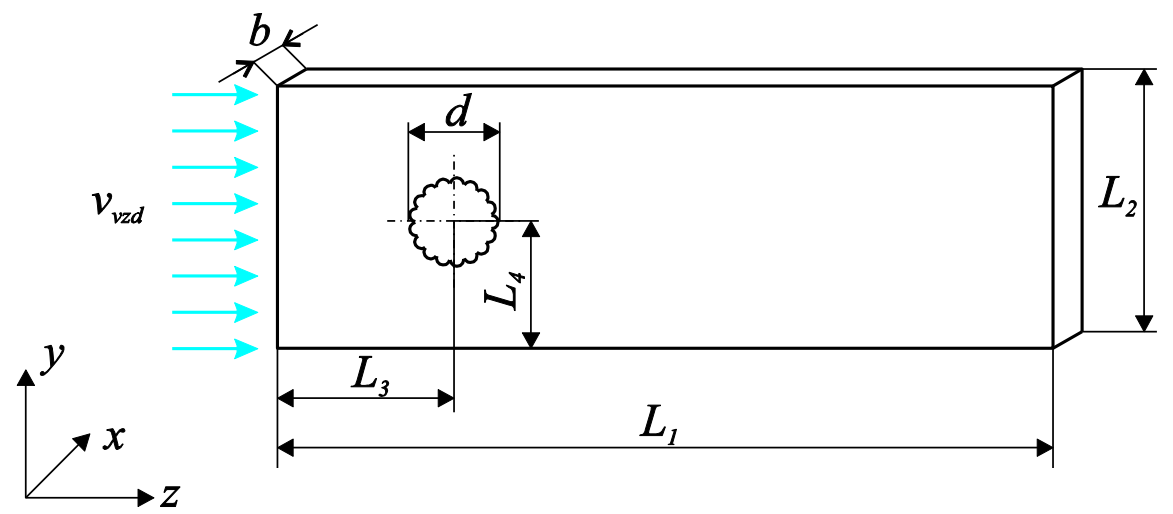

Fig. 2 Model of airflow around the power line cross-section

Parameters of the model are as follows:

- tunnel length: $L_{1}=0.6 \mathrm{~m}$

- height of the tunnel: $L_{2}=0.15 \mathrm{~m}$

- the tunnel depth: $b=0.001 \mathrm{~m}$

- position of the power line cross-section from the beginning of the tunnel: $L_{3}=0.1 \mathrm{~m}$

- position of power line cross-section from the bottom of the tunnel: $L_{4}=0.075 \mathrm{~m}$

- diameter of the conductor AlFe 445/74: $d=0.02963 \mathrm{~m}$

- velocity of air flow: $v_{\text {air }}=1,5,10,15,20,24,26 \mathrm{~ms}^{-1}$

- inlet turbulency: turb $=5 \%$

- turbulence model: $k-\omega$

The simulations are considered for different speeds of air flowing around the conductor cross-section (velocities $v_{\text {air }}=24 \mathrm{~ms}^{-1}$ and $v_{\text {air }}=26 \mathrm{~ms}^{-1}$ represents the maximal air speed for two wind areas in Slovak republic [7]). Numerical simulations were done for the ambient temperature $T=20^{\circ} \mathrm{C}$. Fluid flow is solved by FVM (Finite Volume Method), it is necessary to set up equations for every node of the element of the model.

In CFX there are some requirements of mesh of the model. It should be fine enough to involve all regions with high gradients of velocities of the fluid (near the solid surfaces of the model). Complete mesh of the tunel contains 48261 elements and is shown in Fig. 3 (left), and a detail of the mesh around the conductor cross-section in right. 

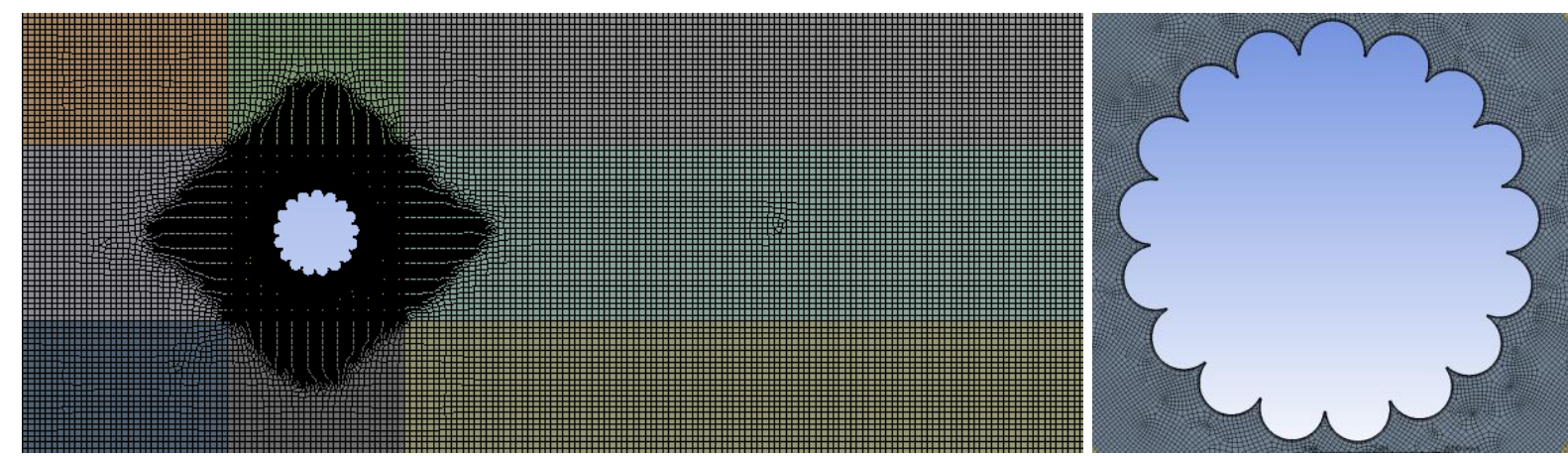

Fig. 3 Mesh of the model (left) and detail of the mesh around the conductor cross-section (right)

The monitored parameters for the simulation quality was the parameter $y^{+}[-]$. For air flow around the AlFe 445/74 power line cross-section the the parameter must be $y^{+}<2$. The values of $y^{+}[-]$for air flow velocity $v_{\text {air }}=20 \mathrm{~ms}^{-1}, v_{\text {air }}=24 \mathrm{~ms}^{-1}$ and $v_{\text {air }}=26 \mathrm{~ms}^{-1}$ are shown in Fig. 4.

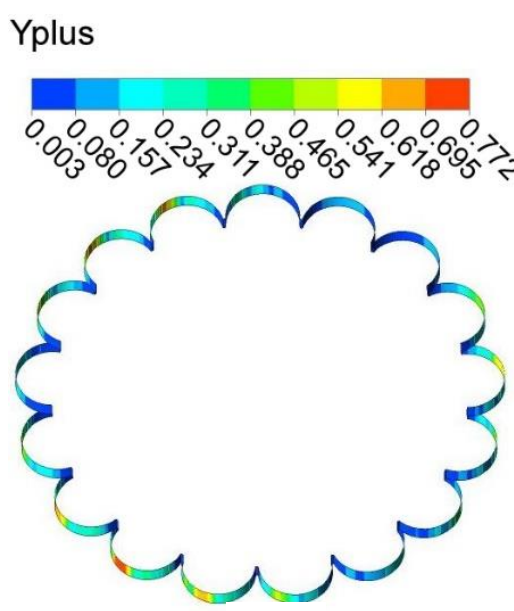

a)

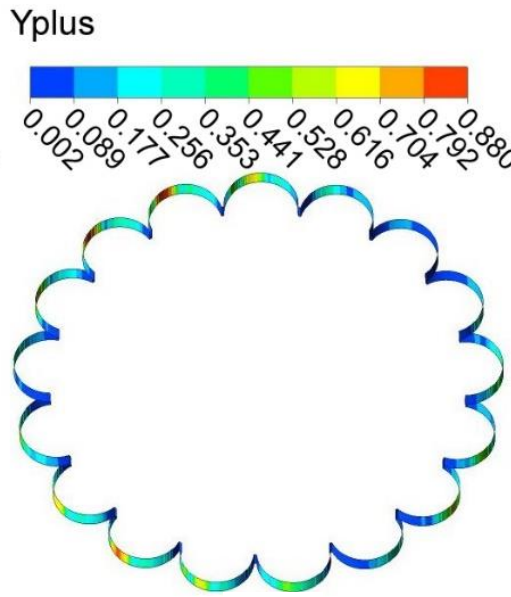

b)
Yplus
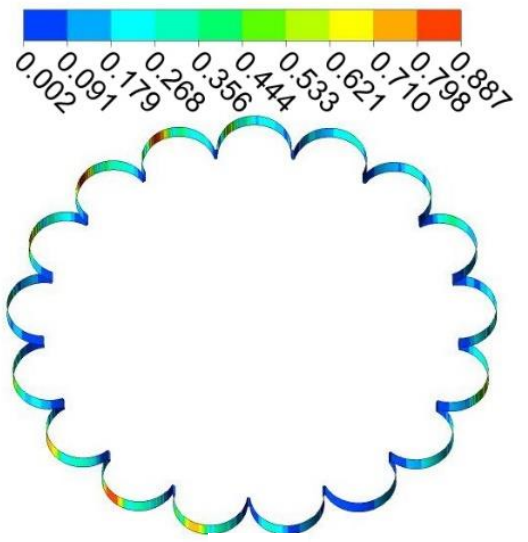

c)

Fig. 4 Values of the $y^{+}[-]$parameter: a) $v_{\text {air }}=20 \mathrm{~ms}^{-1}$, b) $v_{\text {air }}=24 \mathrm{~ms}^{-1}$, c) $v_{\text {air }}=26 \mathrm{~ms}^{-1}$

The distribution of velocities behind the power line cross-section for air flow velocity $v_{\text {air }}=1 \mathrm{~ms}^{-1}$ and $v_{\text {air }}=26 \mathrm{~ms}^{-1}$ is shown in Fig. 5. The distribution of pressure behind the power line cross section for the air flow velocity $v_{\text {air }}=1 \mathrm{~ms}^{-1}$ and $v_{\text {air }}=26 \mathrm{~ms}^{-1}$ is shown in Fig. 6 . The negative value represents the pressure difference against to the reference pressure $p_{\text {ref }}=1 \mathrm{~atm}=101325 \mathrm{~Pa}$. The effects that appear on the edge of the simulation domain (e,g. Fig. 5b) have insignificant influence on the oscillation of the power line caused by airflow.

Periodical vortex separation causes periodical force to the power line with the same frequency and the main direction of the force action is perpendicular to the flow direction. The wire is pushed by significant force in the direction of air flow, but the oscillation of the power line in the direction of flow is small and the frequency is approximately two times the frequency of the vortex separation. 
a)

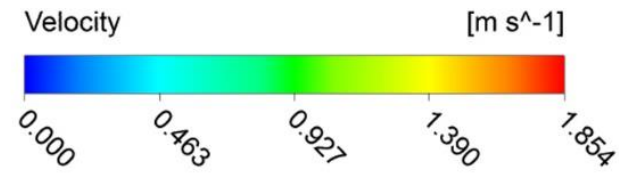

b)
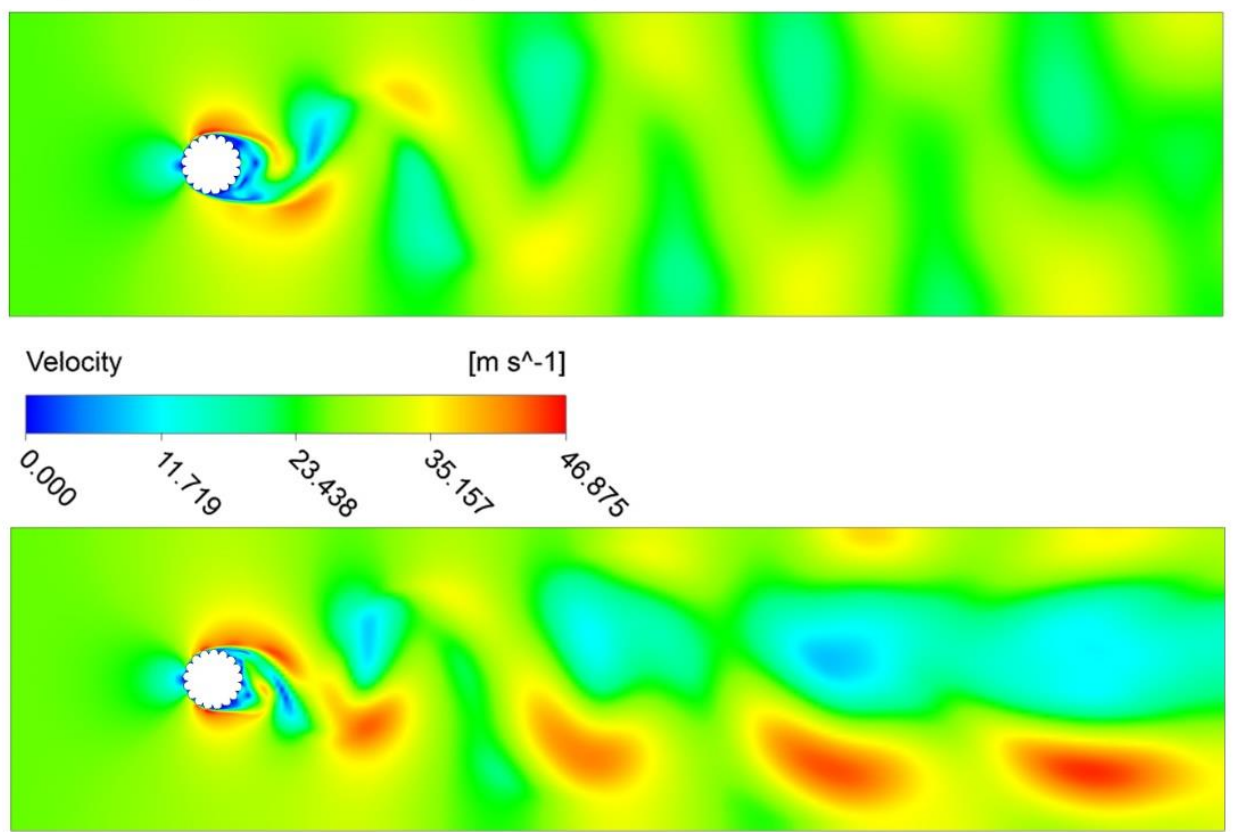

Fig. 5 Distribution of velocities of air flow: a) $v_{\text {air }}=1 \mathrm{~ms}^{-1}$ b) $v_{\text {air }}=26 \mathrm{~ms}^{-1}$

a) Pressure

$[\mathrm{Pa}]$
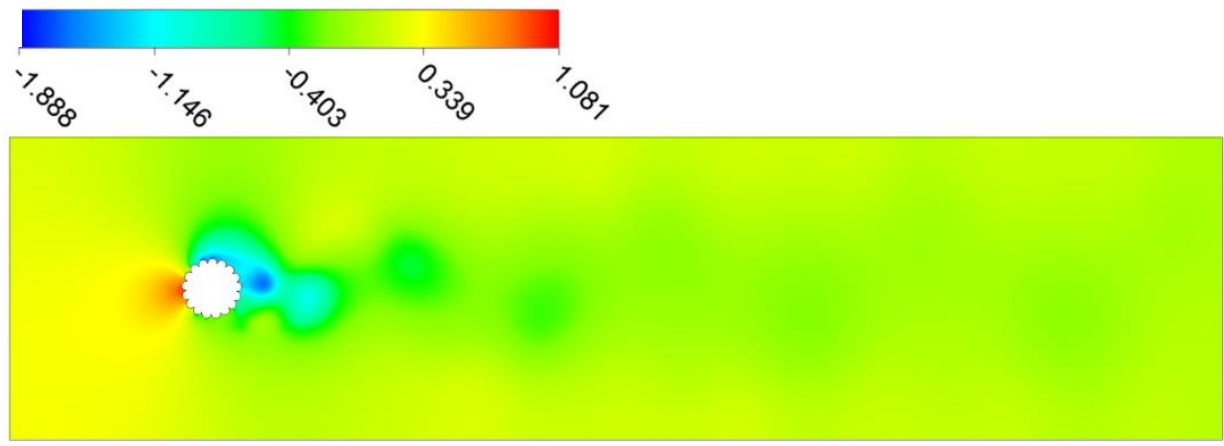

b)

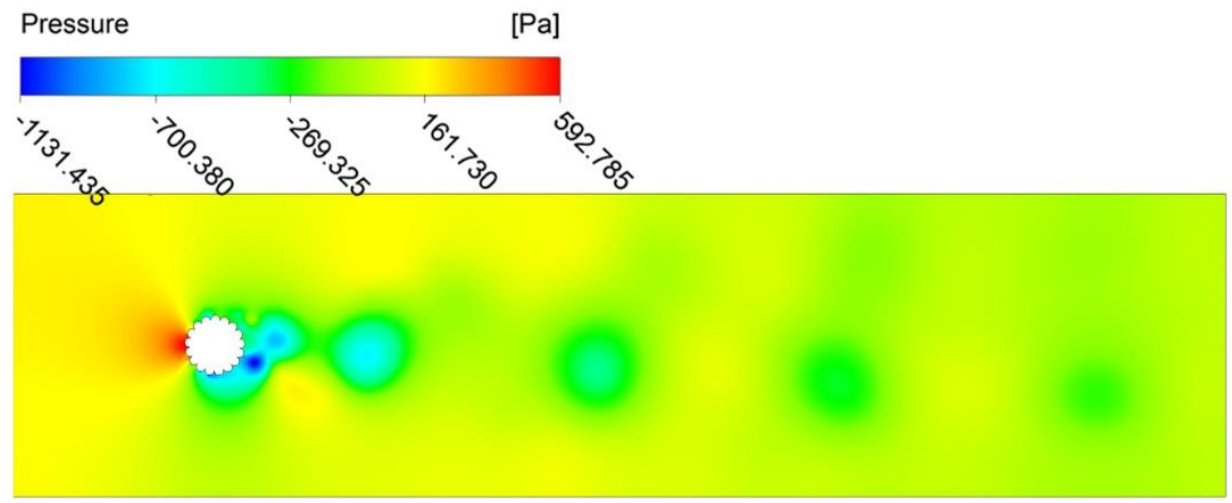

Fig. 6 Distribution of pressure: a) $v_{\text {air }}=1 \mathrm{~ms}^{-1}$ b) $v_{\text {air }}=26 \mathrm{~ms}^{-1}$

The obtained results from the CFX analysis were converted to the horizontal and vertical forces per unit length of the power line. The time dependency of the horizontal and vertical 
forces to the power line per unit length when the air is flowing around the cross-section for $v_{\text {air }}=1 \mathrm{~ms}^{-1}$ is shown in Fig. 7.
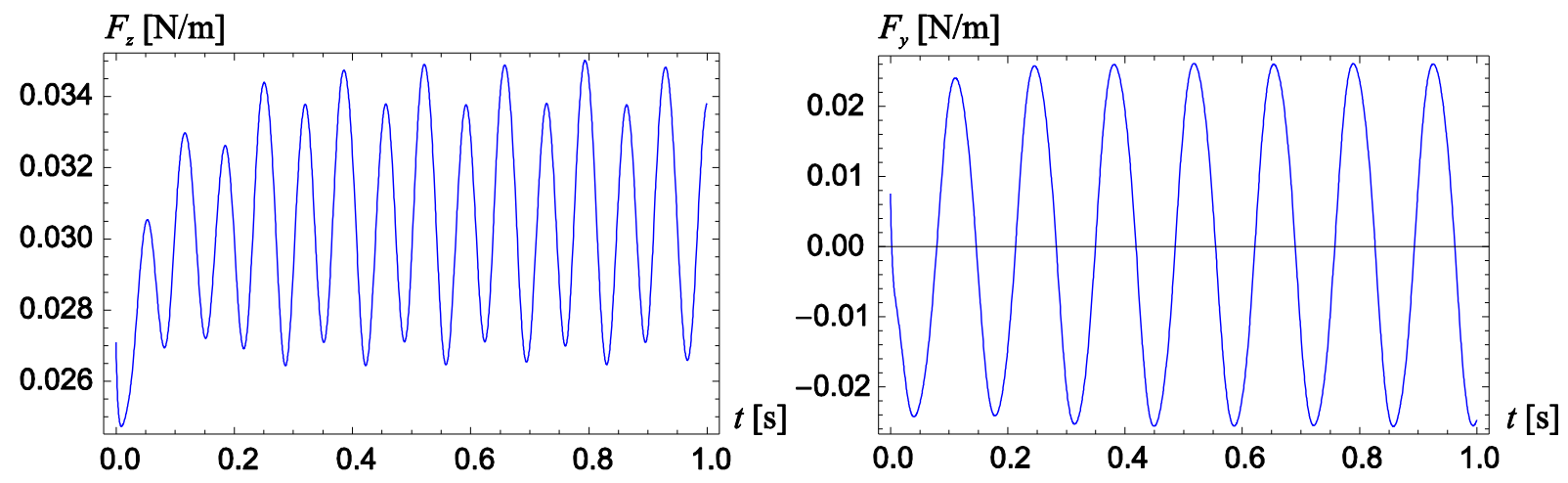

Fig. 7 Time dependency of horizontal (left) and vertical (right) excitation forces for $v_{\text {air }}=1 \mathrm{~ms}^{-1}$

Analytical relationship between geometry of the circular wire, velocity of the flow and frequency of the Karman Vortex Street is according to [8,9]:

$$
f_{\text {yan }}=S_{r} \frac{v_{\text {air }}}{d}
$$

where $S_{r}[-]$ is the Strouhal number, $v_{\text {air }}\left[\mathrm{ms}^{-1}\right]$ is the air velocity, $d[\mathrm{~m}]$ is the wire diameter and $f_{\text {yan }}[\mathrm{Hz}]$ is analytically calculated frequency of force to the cylinder in perpendicular direction to the flow.

For other velocities of air flow $v_{a i r}$, horizontal $F_{z}$ and vertical $F_{y}$ forces acting to the power line have the same character as for the air flow velocity $v_{\text {air }}=1 \mathrm{~ms}^{-1}$ but have different frequencies and amplitudes (Tab. 1 and Fig. 8). The airflow around the ACSR power lines induce a vibration and change of horizontal and vertical forces acting on the power line with some frequency, which increase with the air flow velocity. With increasing of the air flow velocity the frequency of von Karman vortexes and also the amplitude of acting periodic forces (Fig. 8) increase.

Tab.1 Comparison of analytical $f_{y a n}[\mathrm{~Hz}]$ and numerically calculated frequency of horizontal $f_{z}[\mathrm{~Hz}]$ and vertical forces $f_{y}[\mathrm{~Hz}]$ depending on air flow velocity

\begin{tabular}{|c||c||c|c|}
\hline \multirow{2}{*}{$\begin{array}{c}\text { Air flow velocity } \\
\boldsymbol{v}_{\text {air }}\left[\mathbf{m s}^{-1}\right]\end{array}$} & $\begin{array}{c}\text { Analytical calculation } \\
\boldsymbol{f}_{\text {yan }}[\mathbf{H z}]\end{array}$ & \multicolumn{2}{|c|}{ ANSYS CFX } \\
\cline { 2 - 4 } & 7.056 & $\boldsymbol{f}_{\boldsymbol{z}}[\mathbf{H z}]$ & $\boldsymbol{f}_{\boldsymbol{y}}[\mathbf{H z}]$ \\
\hline 1 & 33.602 & 14.806 & 7.353 \\
\hline 5 & 67.204 & 79.872 & 38.970 \\
\hline 10 & 100.811 & 232.234 & 78.864 \\
\hline 15 & 134.408 & 323.415 & 118.906 \\
\hline 20 & 161.289 & 377.358 & 158.983 \\
\hline 24 & 174.726 & 420.168 & 207.727 \\
\hline 26 & & & \\
\hline
\end{tabular}




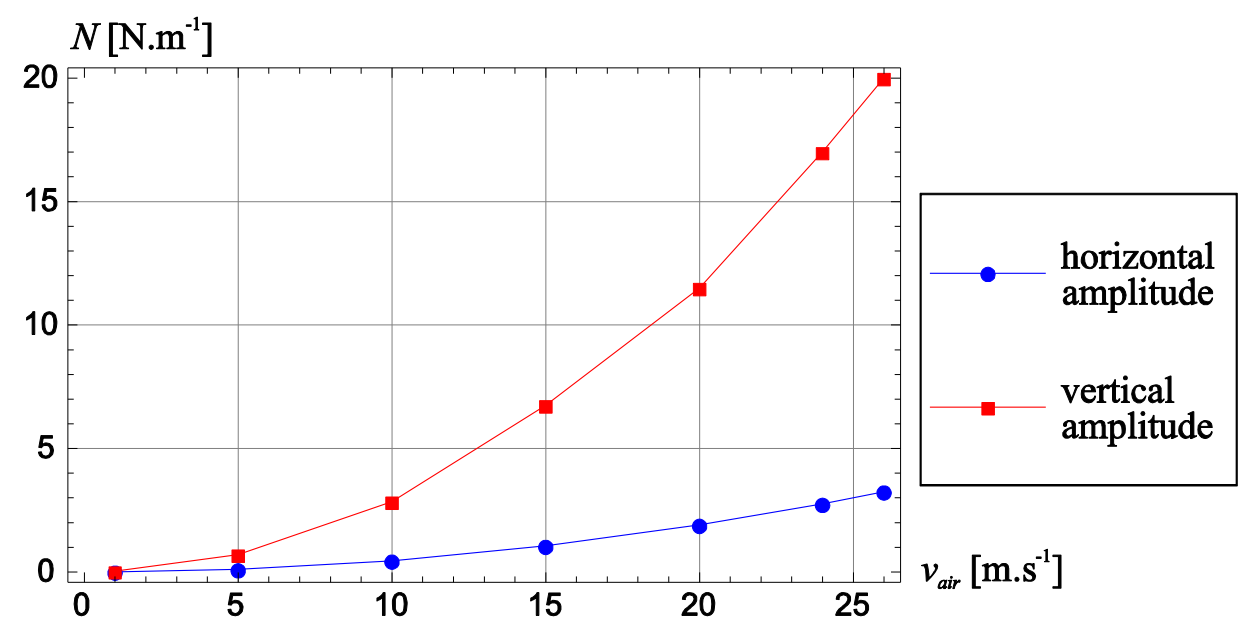

Fig. 8 Horizontal and vertical amplitudes of excitation forces acting to the power line at various air flow speed

The difference between vertical frequencies calculated analytically $f_{\text {yan }}[\mathrm{Hz}]$ and obtained by numerical simulations $f_{y}[\mathrm{~Hz}]$ is due to the fact that in analytical calculations the circular cross-section with a smooth surface has been considered, whereas in CFX simulation the geometry, which is very similar to the real, has been used (Fig. 3 - right).

\section{Modelling of airflow around unsymmetric multi-span}

By applying of dynamic forces obtained from previous analyses to the overhead power lines it is possible to monitor the displacements of the power lines, the axial forces and mechanical stresses at the points of attachment.

The unsymmetric multi-span according to Fig. 9 has been considered. The length of the multi-span is $2 L=600 \mathrm{~m}$ with different height of the points of attachment, in this case $h=20 \mathrm{~m}$. The deflections of the multi-span are: $y_{x 1}=8.374 \mathrm{~m}$ (in the distance from the point A $x_{A}=150 \mathrm{~m}$ ) and $y_{x 2}=1.410 \mathrm{~m}$ (in the distance from the point A $x_{B}=360.343 \mathrm{~m}$ ).

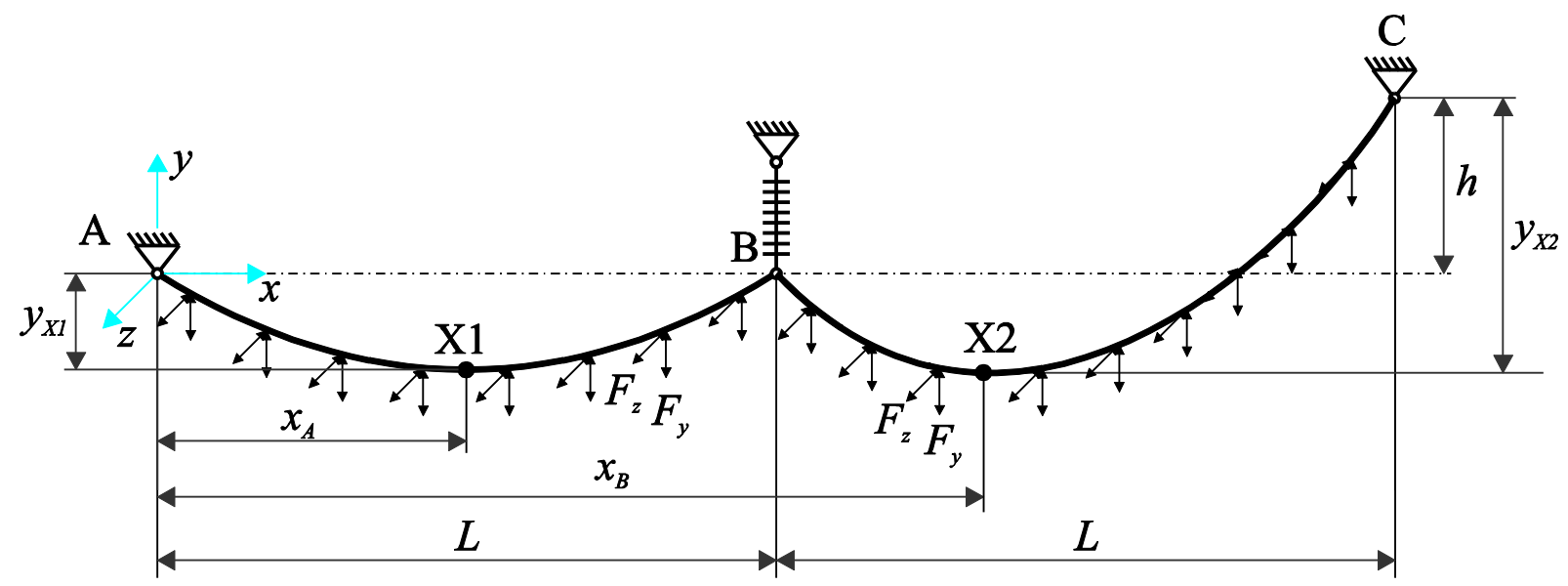

Fig. 9 Unsymmetric multi-span with horizontal and vertical dynamic forces

The modelled symmetric conductor marked as AlFe 445/74 that is constructed from $3+9$ steel and 11+17 aluminum wires (Fig. 10) has been considered. The diameter of the aluminum wires is $d_{A l}=4.5 \mathrm{~mm}$ and the diameter of the steel wires is $d_{F e}=2.8 \mathrm{~mm}$. Material properties of the used materials are $[10,11]$ : 
- aluminium:

- the elasticity modulus: $E_{A l}=69000 \mathrm{MPa}$

- the Poisson's ratio: $\quad v_{A l}=0.33$

- the mass density: $\quad \rho_{A l}=2703 \mathrm{~kg} \cdot \mathrm{m}^{-3}$

- steel:

- the elasticity modulus: $E_{F e}=207000 \mathrm{MPa}$

- the Poisson's ratio $\quad v_{F e}=0.28$

- the mass density $\quad \rho_{F e}=7780 \mathrm{~kg} \cdot \mathrm{m}^{-3}$

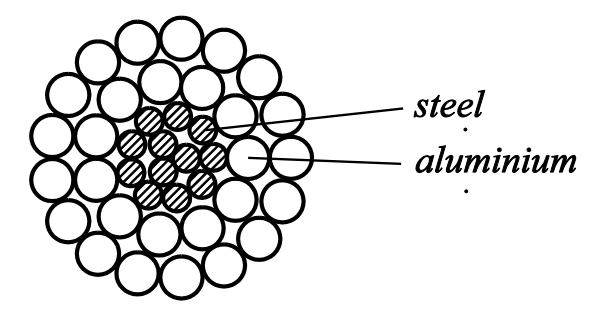

Fig. 10 Conductor AlFe 445/74 cross-section

It is complicated to model a real conductor due to its inhomogeneous material (Fig. 10). Therefore a simplified model obtained by homogenization $[12,13]$ of material properties are used.

The effective cross-section of the conductor parts are: $A_{F e}=73.89 \mathrm{~mm}^{2}$, $A_{A l}=445.32 \mathrm{~mm}^{2}$ and the effective cross-sectional area of the conductor is $A=519.21 \mathrm{~mm}^{2}$. The effective quadratic moments of the conductor cross-sectional area are: $I_{z}=I_{y}=28528.3 \mathrm{~mm}^{4}$. The effective circular cross-section is constant with diameter $d_{e f}=25.71 \mathrm{~mm}$ and the deformed length of the power line is $L_{d}=300.62 \mathrm{~m}$. The effective material properties of the used power line are $[12,13,14]$ :

$$
\begin{gathered}
E_{L}^{M_{y} H}=E_{L}^{M_{z} H}=47929.78 \mathrm{MPa} \\
v_{L}^{N H}=0.323 \\
\rho_{L}^{N H}=3482.81 \mathrm{kgm}^{-3}
\end{gathered}
$$

Here $E_{L}^{M_{y} H}=E_{L}^{M_{z} H}$ is the elastic modulus for bending about axis $y$ and $z$, respectively. $v_{L}^{N H}$ is the effective Poisson ratio and $\rho_{L}^{N H}$ is the mass density for axial loading. These effective material properties have been used in the transient analyses of the single power line. Transient analyses of the air flow over the single power line cross-section have been done with a mesh 2400 of BEAM188 elements of the FEM program ANSYS [6].

The horizontal and vertical excitation forces from the ANSYS CFX were applied to the model of the power line created in ANSYS APDL [6]. The horizontal forces were applied as force $F_{z}\left[\mathrm{Nm}^{-1}\right]$, the vertical forces were applied as force $F_{y}\left[\mathrm{Nm}^{-1}\right]$ (as shown in Fig. 9). Numerical simulations were performed for air flow velocities $v_{\text {air }}=24 \mathrm{~ms}^{-1}$ and $v_{\text {air }}=26 \mathrm{~ms}^{-1}$ (the horizontal and vertical amplitudes of the excitation forces were much greater for these velocities than for other ones) that represents the maximal speeds for two wind areas in SR [7]. The vertical and horizontal displacements of the points X1, X2 and B are shown in Fig. 11 and Fig. 12. The axial forces at the points of attachment (points A, B and C) are shown in Fig. 13. 


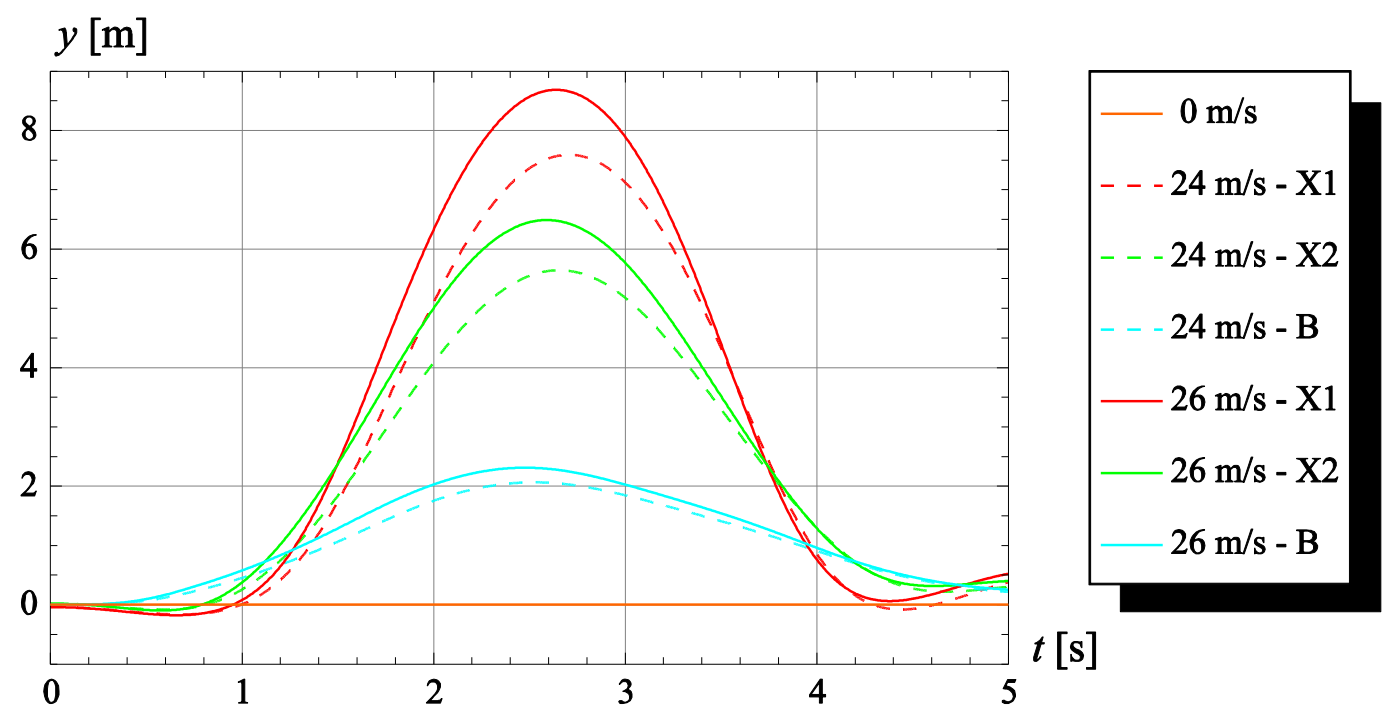

Fig. 11 Vertical displacement of the points X1, X2 and B on the power line

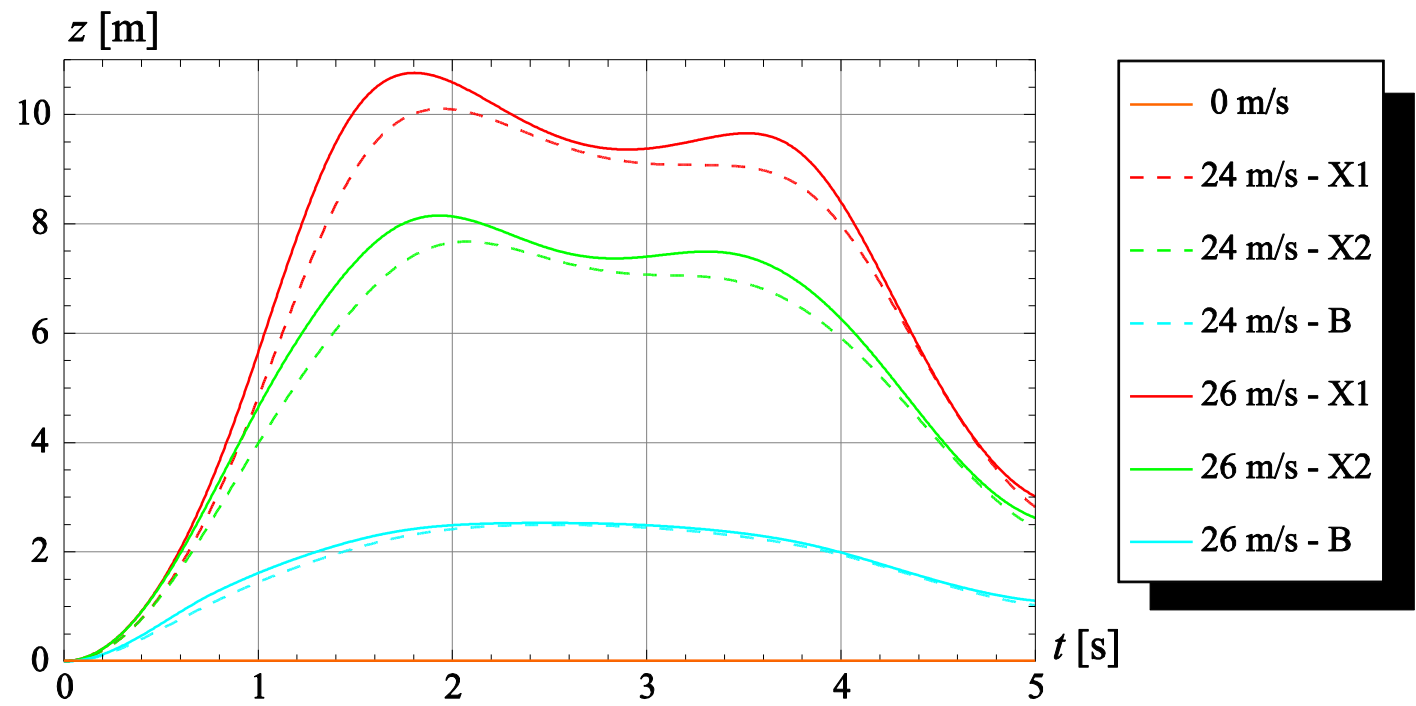

Fig.12 Horizontal displacement of the points X1, X2 and B on the power line
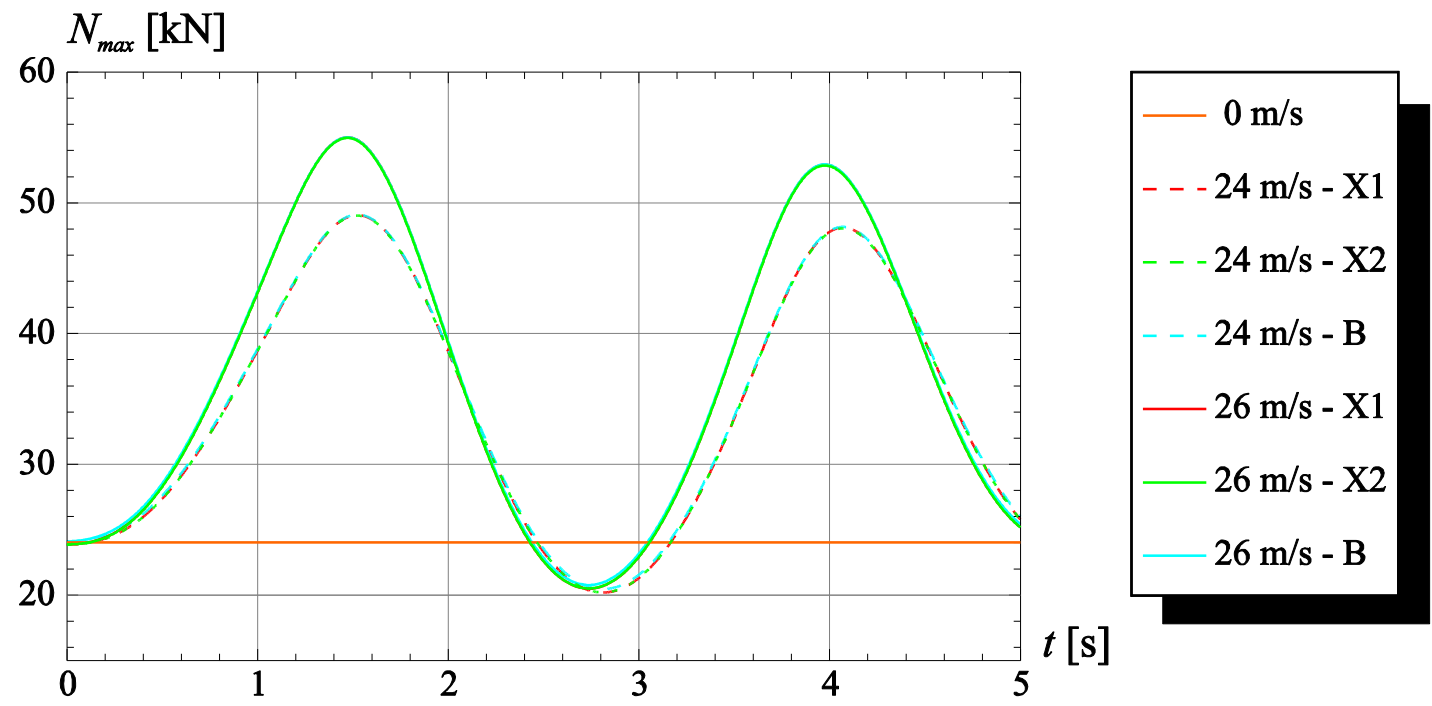

Fig. 13 Transient axial forces in the attachments 


\section{Conclusion}

In this contribution the transient analysis of dynamic forces from the air flow to the power line is calculated. In the numerical analysis the influence of the wind velocity to the excited frequency of the ACSR power line was studied. The numerical calculation has been done in commercial software ANSYS CFX and ANSYS Mechanical APDL [6]. From the numerical simulation the following results are obtained:

- Increase of the air flow velocity increases the power line cross-section frequency of von Karman vortexes and also the amplitude of acting periodic forces increase,

- the amplitudes of the vertical acting periodic forces are significantly greater that amplitudes of the horizontal acting periodic forces,

- the excited frequencies in the horizontal direction are approximately two times greater that the excited frequencies in the vertical direction,

- the deflection in the plane $x y$ and $x z$ from steady state depends on the velocity of the air, higher velocity causes that power line deflect more in the horizontal and vertical planes,

- the maximal axial forces are reached for air flow speeds $v_{a i r}=26 \mathrm{~ms}^{-1}$ at points the attachment (on insulator).

\section{Acknowledgement}

This work was supported by the Slovak Research and Development Agency under the contract No. APVV-0246-12 and APVV-14-0613, by Grant Agency VEGA, grant No. $1 / 0228 / 14$ and 1/0453/15.

\section{References}

[1] White F.M.: Fluid Mechanics, 3rd. ed., pp 269-270, McGraw-Hill New York (1994)

[2] Hung P.V., Yamaguchi H., Isozaki M., Gull J. H.: Large amplitude vibrations of longspan transmission lines with bundled conductors in gusty wind. Journal of Wind Engineering and Industrial Aerodynamics, 126 (2014) 48-59.

[3] Wang J.: Overhead Transmission Line Vibration and Galloping. International Conference on High Voltage Engineering and Application, Chongqing, China, November 9-13, 2008.

[4] Chunming W., Bin M., Tingting S.: Research on the Wind-induced Vibration Coefficient of Transmission Tower-line System, Physics Procedia. 24 (2012) 149-154.

[5] Zhou L., Yan B., Zhang L., Zhou S.: Study on galloping behavior of iced eight bundle conductor transmission lines, Journal of Sound and Vibration, 362 (2016) 85-110.

[6] ANSYS Swanson Analysis System, Inc., „ANSYS Mechanical APDL Structural Analysis Guide," ANSYS, Houston.

[7] STN EN 50341-1, Overhead electrical lines exceeding AC 45 kV. Part 1: General requirements. Common specifications, 2006.

[8] Irvine T.: Transmission Line Vibration, Vibrationdata, May 2006. [Online]. Available: www.vibrationdata.com/Newsletters/May2006_NL.pdf. [Cit. 2006].

[9] Paulech J., Lago J., Kutiš V., Stančík S., Fric R., Murín J.: CFD Simulation of Air Flow around Overhead Power Lines, Bratislava, 2010.

[10] STN EN 50189, Conductors for overhead lines - Zinc coated steel wires, 2001.

[11] STN EN 60889, Hard-drawn aluminium wire for overhead line conductors, 2001. 
[12] Murín J., Kutiš V. Improved mixture rules for the composite (FGM's) sandwich beam finite element, Barcelona, Spain, 2007, 647-650.

[13] Murín J., Aminbaghai M., Hrabovský J.: Elastostatic Elastostatic Analysis of the Spatial FGM Structures. Strojnicky časopis - Journal of Mechanical Engineering, 65(1), 27-56. 2016, doi: 10.1515/scjme-2016-0003

[14] Murín J., Hrabovský J., Gogola R., Gálik G.: Modal analysis of the power lines by finite element methods, rev. EE časopis pre elektrotechniku, elektroenergetiku, informačné a komunikačné technológie, Trenčín, 2014. 